\title{
Schumpeterian Behavior in a CPR Game: Experimental Evidence from Colombian Fisheries Under TURF's Management
}

\author{
José Santiago Arroyo-Mina \\ Professor and Regional Project Manager, \\ Universidad del Valle, Colombia \\ Daniel Guerrero \\ Doctorate Student, \\ Universitat Autonoma de Barcelona, Spain \\ Corresponding Author
}

Doi: $10.2478 / m j s s-2018-0120$

\begin{abstract}
This paper studies the behavior of Pacific-Colombian fishermen in a Common-Pool Resource game. The results show that decision-making depends on fishermen's schooling, sex and last round payoffs. Focusing on individual information, we observe that human capital, measured in years of schooling, has a significant effect on decision-making. Specifically, players with higher schooling adjust their decisions towards on lower levels of harvest, leading closer to the cooperative solution. This behavior could be explained by the better-educated subjects' improved understanding of the information available to them and possible coordination of efforts due to TURF-based management in the zone.
\end{abstract}

Keywords: Common-Pool Resources, Non-cooperatives Games, Human Capital, Fishery, Agricultural Policy

\section{Introduction}

Research on harvesting by conducting Common-Pool Resource (CPR) games has often focused on the nature and role of relevant institutions; while more recently, a behavioral economics approach has been increasingly adopted (Anderies et al., 2011), presenting findings concerning on how individuals process information, how they make decisions and how they respond to changes in incentive structures (Ostrom, Walker, and Gardner, 1992). Particularly, in most of the cases, the context adopted is a repeated Prisoner's Dilemma (PD), where the predicted outcome is Nash Equilibrium, unless players find ways for tacitly or explicitly cooperating. A popular research strategy has been to study the behavior of subjects in CPR-games with a static baseline framework inspired on a real-world situation relevant to the subjects' every-day decision-making environment. In fact, some authors argue that individual behavior in such contexts reflects subjects' preferences, values, and actual experience with the resource from their daily lives (Cardenas, 2001; Cardenas and Ostrom, 2004)

Among the most robust findings these experiments have provided is that communication increases cooperation. This means that, when participants are allowed to communicate face-toface, the harvest declines towards the cooperative equilibrium (Ostrom and Walker, 1991; Ostrom, Walker and Gardner, 1992; Ostrom, Gardner, and Walker, 1994). Some reasons for explaining this behavior can be found in that communication helps individuals to detect the actions of others with whom they are interacting, allowing individuals to elicit commitments, creating a process of 
moralization among players and a sense of group identity.

Following the results provided by Ostrom et al. (1994), many experiments have been run in Colombia with different findings. For instance, the perceived inequality in the group constrains the effectiveness of communication (Cardenas, 2003). Additionally, if the optimal decision for cooperative equilibrium is modestly enforced, the harvest is lower than if individuals were allowed to have face-to-face communication (Cardenas, 2001); even a combination of internal communication and external non-coercive intervention leads to better results (Moreno-Sanchez and Maldonado, 2010).

However, findings regarding the effect of individual information such as schooling on decisionmaking have not been yet conclusive; i.e. is not yet clear whether education enhances willing to cooperate or defect in a collective-action problem. Although some conclusions reported that schooling and training have certain influence in reducing the harvest, because these more schooled individuals are open to accepting external interventions and rules aimed at the sustainable use of resources. Nevertheless, these variables showed a non-significant relation to harvesting (MorenoSanchez and Maldonado, 2010).

Besides, higher levels of education bring a greater commitment to sustainable harvest decisions (Arroyo-Mina, Revollo-Fernandez, Aguilar-Ibarra, and Georgantzis, 2016), enhance prosocial values like reciprocity, inhibit antisocial behavior, enhance willingness to contribute to collective actions (Cardenas, Chong, and Ñopo, 2009; Brañas, Cardenas, and Rossi, 2009), and decrease free-riding (Brañas et al., 2009).

However, education has a positive and significant relation to the harvest in the experiment when more schooled individuals have advantage over less schooled participants (Velez, Stranlund, and Murphy, 2009). Somehow, less schooled individuals may be unsure about their decisions and use the decisions of others as a guide to their own decision-making. This strategy is a sort of confirmation of a dominant preference leading to conditional cooperation.

Experimental literature in the study of CPR-games has demonstrated that face-to-face communication and other external regulations lead to a higher probability to solve the commons dilemma, although findings on CPR-games and their education over Colombian villagers are not yet conclusive. However some findings from PD games have confirmed the impact of human capital on cooperative behavior (Schramm, 1998; Brosig, 2002; Burks, Carpenter, and Verhoogen, 2003; Tan and Zizzo, 2008;) and it is often observed that players with higher schooling are better at understanding repeated PD games, being able to cooperate even when they do not know each other, and play only once (Boone et al., 2002; De Jong, 2015). This behavior exhibits that players with higher schooling behave strategically in order to obtain better outcomes, rather than being more altruistic (De Jong, 2015).

However, education is a key point for creating social capital (Putnam, 1995; Alesina and La Ferrara, 2000; Fukuyama, 2002; Dinda, 2008) and development of human capital through education creates social capital as a positive externality (Lucas, 1988), partly because it enhances socialization and reinforces collective behavior (Almond and Verba, 1963; Paulsen, 1991).

We are interested in contributing to this literature by explaining how these decisions are influenced by the accumulation of human capital measured by the years of formal schooling. For this purpose, this paper aims at explaining the findings of a set experiments performed in a Territorial Use Rights for Fisheries (TURF's) based management system in Choco Colombia by replicating social dilemmas (Ostrom et al., 1994; Cardenas, 2001) in a filed lab. Players are a set of fishermen, which perform a pen-and-paper CPR-game conducted in different villages of the Pacific Coast of Colombia, ${ }^{1}$ whose everyday activities involve resource-related decisions regarding the harvest of a CPR. Having no external rules, institutions nor enforcement, we find a negative

\footnotetext{
${ }^{1}$ This research was conducted within the project "Biodiversity Conservation of Utria National Park through the sustainable management of buffer zones, " executed by MarViva in cooperation with Word Wildlife Fund (WWF Colombia), Natural Heritage (Fund for Biodiversity and Protected Areas) and United States Agency for International Development (USAID), with the objective to define activities related to artisanal fisheries management agreements in the Gulf of Tribuga. Therefore, the results of this research may contribute to the design of programs for sustainable fishing in the area and strengthen the governance of local communities for the collective improvement.
} 
relationship between the harvest in a CPR-game and a fisherman's years of schooling; thus, development of human capital.

The remaining part of the paper is structured as follows: Section 2 presents a discussion on the relation of TURF's, and how this mechanism influence behavior of inhabitants Section 3 presents the experimental design and procedures. Section 4 presents results. Section 5 provides the conclusions.

\section{Territorial Use Rights for Fisheries (TURF's) in Colombia: ZEPA and DRMI}

In Colombia, Law 13 of 1990 proposed Exclusive Areas for Artisanal Fishing (ZEPA for its acronym in Spanish) and Regional Districts for Integrate Management (DRMI for its acronym in Spanish) for managing marine areas of fisheries. This law is proposed for complying with the principles and guidelines of the FAO Code of Conduct for Responsible Fisheries (FAO, 1995), which establishes a set of principles to guide the management of fisheries resources towards sustainability (Vieira, Diaz, and Diaz, 2016).

On the one hand, ZEPA process started in July 2008 by defining an area destined to the development of artisanal fishing, traditionally managed by communities inhabiting north coast of Choco Colombia, with initial validity of one year. Later in August 2009, its validity was extended for another year, and in August 2010, for two additional years Finally, declared permanently on July 2013 (MinAgricultura, 2013). The designation of these 2.5 nautical miles wide between the northern limit of the Utria National Natural Park and the border with the Republic of Panama, alleviated in a certain way the rivalry between artisanal and the industrial fishing region (Diaz and Caro, 2016).

On the other hand, DRMI process started more that 20 years ago (CODECHOCO et al., 2014) materialized in December 2014 (Vieira, Diaz, and Diaz, 2016), and legally established in October 2017 (MinAgricultura, 2017). The declaration established a maritime extension of 55,974 hectares for exclusive extractive uses by the inhabitants of north coast of Choco, from Cabo Corrientes to Utria National Natural Park. This declaration aims at regulating gears and arts of fishing in order to promote sustainability of hydro biological resources and other environmental goods and services that support fishing (Vieira, Diaz, and Diaz, 2016).

The territorial designations of these geographic spaces, which connect to each other, were accompanied by workshops about sustainable exploitation, preservation, restoration, knowledge and enjoyment conducted along the communities. The objective of these workshops aims at maintaining the composition and function of natural capital accordingly to cultural values of inhabiting communities.

These designations are defined as Territorial Use Rights for Fisheries (TURF's) with sitespecific management attached to territorial culture. By definition, these are extended economic zones, which rights can be controlled within the territory, with specific conditions for governing access to the resource by communities. TURF-based management systems provide relative rather than absolute controls, preventing the rent dissipation from economic waste due to excess of effort caused at allocating capital and labor (Christy, 1982). Thereby, under TURF-based management, users are responsible for defining and planning exploitation of resource and controlling access (Wilen, Cancino, and Uchida, 2012)

Different studies have found TURF-based management increase compliance behavior of fishers and are supposed to correct the underlying causes of overfishing, the absence of welldefined property rights; although impacts of TURF's on the sustainability of fisheries are subject to debating (Nguyen Thi Quynh et al., 2017). Nevertheless, some studies have found that TURFbased management coordinate fishing effort with the aim of mitigating inefficient allocation of fishing effort in Japan (Gaspart and Seki 2003) and Chile (Cancino, Uchida, and Wilen, 2007).

Researches on communication, enforcement, co-management and compliance behavior are the most explore treatments in experimental economics. However, evidence regarding formation of human capital and the influence on behavior in the context of TURF's has not received much attention. Nevertheless, some findings reported from CPR-games conducted in TURF-based areas show that harvest is negatively related to levels of schooling in Marine Protected Areas (MPA) in Colombia (Moreno-Sanchez and Maldonado, 2010), Management and Exploitation Areas of 
Benthic Resource (MEABR) in Chile (Santis and Chavez, 2015), and Marine Reservoirs (MR) in Mexico (Arroyo et al., 2016).

\section{Experiment Design}

The design aims at studying the behavior of Colombian Pacific fishermen in a CPR-game performed in a field lab. These participants are inhabitants of collective territories, each one with knowledge and entitlement to engage in fishing activity. For this purpose, we use an experimental design similar to Ostrom et al. (1994) and Cardenas (2001) with a modification in the payoffs, without changing the main properties of the original setup. In this experiment, an agent has a range of choices between 1 to 8 units to harvest from a CPR. This choice could also represent units of effort applied to the resource or quantity of inputs used for yielding the resource. ${ }^{2}$

\subsection{Experiment protocol ${ }^{3}$}

The results reported in this study were obtained from pen-and-paper experiments run with 159 fishermen recruited among the communities of the Colombian Pacific Coast during April $2012 .{ }^{4}$ In each session, groups of 5 players were formed, each one assisted by a researcher. Before starting the game, the context of the experiment and the rules to follow were presented to fishermen. During these experiments, anonymity was enforced. Decisions were made in secret, and even though many players knew each other, communication during the experiment was strictly forbidden. It was clearly explained to them that individual payoffs at the end of the session would depend on their own and rivals' harvest. All payoffs were made effective at the end of each session. ${ }^{5}$

\subsection{Instructions and decisions}

Instructions and decisions sheets were provided to each fisherman, on which they had to indicate their harvest level in each period. They also had to annotate individual and aggregate harvest, but they were not offered feedback on the others' individual harvest. They were also offered a payoffs sheet indicating the earnings for different combinations between individual and collective harvest.

Although each session consisted of a 20-period decision-making task, we focus here on the first 10 periods exclusively. Rounds 11-20 were dedicated to other research outside of the scope of this work. ${ }^{6}$

In this experiment, individual harvest ranged between $1 \leq x_{i} \leq 8$ and aggregate harvest between $5 \leq \sum x_{j} \leq 40$ units. Then, as proposed by Cardenas (2001), individual payoff $\pi_{i}$ is given by:

$\pi_{i}=f\left(x_{i}, \sum x_{j}-x_{i}\right)$

which ranges between a minimum of 50 payoffs when individual harvest $x_{i}=1$ and aggregate rivals' harvest $\sum x_{j}-x_{i}=32$, and a maximum of 1730 payoffs when individual harvest $x_{i}=8$, and aggregate rivals' harvest $\sum x_{j}-x_{i}=4{ }^{7}$

\section{Results}

In the experiment we ensure to have individual information from legal-aged fishermen who have

${ }^{2}$ The theoretical model implemented is adapted from Cardenas (2001) and described in detail by Georgantzis, Arroyo, and Guerrero (2013).

${ }^{3}$ In the Appendix Section, we provide details on the experimental protocol, instructions, and decision and payoffs sheet.

${ }^{4}$ These communities are Panguí, Coquí, Joví, Arusí, Termales, Nuquí, Jurubirá, Tribugá y El Valle. All of them are located in the Gulf of Tribuga.

${ }^{5}$ The accumulated experiment points of each participant were converted into a real monetary reward in Colombian Pesos, and paid at the end of the experiment. The average individual payoff was US\$14.

${ }^{6}$ Regulations under uncertainty associated to climate change.

${ }^{7}$ Points are converted into Colombian Pesos: 1 point $=\$ 1$ COP The exchange rate by date was around $\$ 1800$ COP/USD. 
received earnings from the activity at least once in their lives. The information was privately collected through a semi-structured survey conducted at the end of the experiment. Some other prior descriptive analyses of the experiment are presented in this section.

\subsection{Descriptive analysis}

Table 1, contains descriptive statistics of the overall sample of 159 fishermen. These fishermen reported their age, years of schooling, payoffs obtained during the experiment and sex. In this sample 143 are men.

Table 1: Summary of fishermen information

\begin{tabular}{lcccc}
\hline Variable & Average & St. Deviation & Min. & Max. \\
\hline \hline Individual harvest & 4.560 & 2.188 & 1 & 8 \\
Years of schooling & 6.214 & 3.869 & 0 & 16 \\
Payoffs per round & $1,014.943$ & 241.867 & 100 & 1,730 \\
Total payoffs & $10,149.43$ & $1,430.091$ & 7,100 & 13,680 \\
\hline
\end{tabular}

Source: Own elaboration.

Distribution frequency of year of schooling is presented in figure 1. Particularly, the highestoccurring amount of years of schooling is grade 11 . This indicates that the $25 \%$ of the participants have already finished high school. The second-most occurring amount of years of schooling is grade 5 . This indicates that $15 \%$ of the participants have already finished elementary school. In this sample, two fishermen had a non-complete technician course, whereas one fisherman had obtained the technician degree. ${ }^{8}$

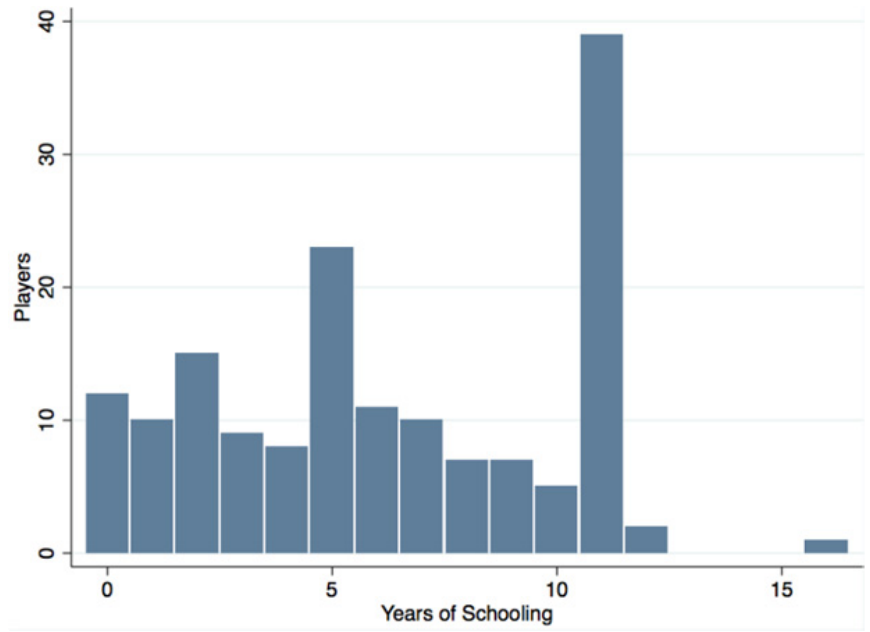

Figure 1: Distribution of Years of Schooling in sample players

Source: Own elaboration.

By running different local regression, we identify nonlinear relationships between harvest and explanatory variables; these patterns exhibit how players behaved during the CPR-game.

\footnotetext{
${ }^{8}$ In Colombia, a technician degree is an undergraduate program that takes up to three years of schooling. This program is not considered a Bachelor, which takes five years to be obtained.
} 
a) Difference in Payoffs vs. Harvest

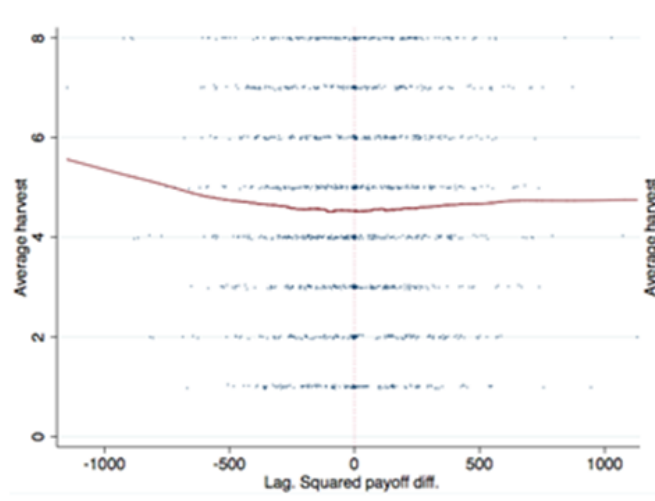

b) Years of Schooling vs. Harvest

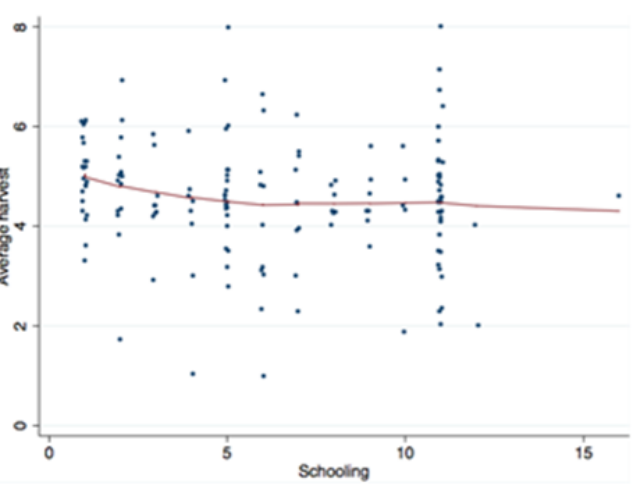

Bandwidth, 0.8

Figure 2: Harvesting behavior

Source: Own elaboration.

In figure 2, Panel a shows that average harvest increases when the difference in payoffs form past round is different than zero. Particularly, harvest tends to increase the higher when payoffs diminish. Panel $b$ shows that players who have more years of schooling display a non-linear pattern of diminishing average harvest.

\subsection{Statistical analysis}

We analyze longitudinal data obtained from individuals making decisions during the experiment, and demographic variables by estimating Pooled OLS clustering for players, random effects (RE) model, and a panel Tobit with lower limit 1 and upper limit 8. We estimated individual $x_{i}$ harvest as dependent variable. Squared lag of difference in payoffs is estimated as independent-explanatory variables. Finally we introduce years of schooling and sex as control variables.

The variable years of schooling as a proxy of human capital is transformed into natural logarithms in order to capture the non-linear relation with harvest. Sex, $s$, is a dichotomous variable that takes values of 1 for male subjects, 0 otherwise. Finally, the squared lag of difference in payoffs identifies how incentives motivate decisions. The results of these estimations are presented in table 2.

Table 2: Panel data estimations

\begin{tabular}{|c|c|c|c|c|}
\hline Variable $^{a}$ & & OLS & RE & Tobit \\
\hline 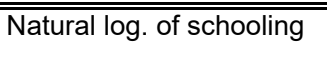 & $I s c$ & $\begin{array}{c}-0.236^{\star *} \\
(0.099)\end{array}$ & $\begin{array}{c}-0.236^{\star \star} \\
(0.099)\end{array}$ & $\begin{array}{c}-0.263^{\star \star} \\
(0.151)\end{array}$ \\
\hline Sex & $s$ & $\begin{array}{l}0.621^{* \star} \\
(0.278)\end{array}$ & $\begin{array}{l}0.631^{* *} \\
(0.281)\end{array}$ & $\begin{array}{l}0.839^{\star *} \\
(0.412)\end{array}$ \\
\hline $\begin{array}{l}\text { Squared lag of difference } \\
\text { in payoffs }\end{array}$ & $1 . d p^{2}$ & $\begin{array}{c}7.78 e^{-07} \\
\left(4.90 e^{-07}\right)\end{array}$ & $\begin{array}{l}1.14 e^{-06 * *} \\
\left(4.55 e^{-07}\right)\end{array}$ & $\begin{array}{c}1.46 e^{-06 * * *} \\
\left(5.33 e^{-07}\right)\end{array}$ \\
\hline Average harvest & Constant & $\begin{array}{c}4.327^{* * *} \\
(0.301)\end{array}$ & $\begin{array}{l}4.29^{* * *} \\
(0.305)\end{array}$ & $\begin{array}{l}4.15^{* * *} \\
(0.465)\end{array}$ \\
\hline
\end{tabular}

${ }^{a}$ Independent variable: Individual harvest $x_{i}$

*Statistically significant at $10 \%$. ${ }^{* *}$ Statistically significant at $5 \%$. ${ }^{* *}$ Statistically significant at $1 \%$

Source: Own elaboration. 
These results allow us to analyze the behavior of the fishermen during the first 10 rounds of the experiment, were no harvest levels are suggested nor enforced. As stated in the table 2, the years of schooling have a significant effect on players' decision-making during the experiment exhibiting a negative relationship with the harvest.

It is possible to assume that more schooled participants are led to reduce their harvest in the search of higher payoffs through a better understanding of the dynamics of the game, as Boone et al. (2002) state. Thereby, it is possible to conclude that players with more years of schooling assume that reducing harvest produces higher payoffs, and their decisions have led towards the cooperative solution.

We presume that more schooled players make these decisions because of a better understanding of the information provided, and better processing the feedback from their own game interactions. This behavior could be explained by the cognitive advantage schooling brings to more educated players, in information processing and finally maximizing their well-being through problem solving and better adaptation to new situations (Bowen, 1977; Pallas, 2000; Pallas, and Jennings, 2009). Considering this, the more schooled players can have better understanding of the information presented to them at the beginning of the experiment, especially regarding payoffs and how these are obtained. Due to this, players can have more accurate expectations of other players' decisions.

Furthermore, it is necessary to indicate that during the experiment, it is observed that players who develop basic cognitive abilities had a noticeable advantage for reaching better outcomes over those less schooled players. On the one hand, the less schooled players had some deficiencies in core subjects like reading, writing, and math. This indicates that a short schooling period had some immediate effect on players' performance in the experiment. On the other hand, more schooled players had the ability to improve their results by taking the time to read and analyze the payoffs structure. It should be noted that during the sessions, more schooled players made math operations from time to time during every round, while less schooled players did not.

By analyzing the difference in harvest during the experiment, we notice that tends to accumulate around 0 , and strategies tend to remain in the same, deviating no more than 1 unit; on average $\overline{\Delta x}$ remains around 0.006 , with an interval confidence at $95 \%$ significance $-0.141<\overline{\Delta x}<$ 0.152 ; standard deviation 0.075 .

This behavior is denominated Schumpeterian ability to deal with payoffs disequilibria, in which players search for more profitable opportunities spatially dispersed in a region around their decision, and relocating at a given rate per period. This search consists in a random decision, in which the quantity of harvest is not subject to enforceable contracts; thus followed by one round of inspection and relocation to a new decision in its immediate neighbors with a higher harvest (Bowles, Gintis, and Osborne, 2003).

However, players differ in their ability to identify and capture these disequilibria due to personal dispositions and capacities attributed to economic return of schooling and the enhancement of these abilities through education; this difference is denominated Allocative Effect of Schooling (Welch, 1970).

Considering previous findings of Velez et al. (2009), and Moreno-Sanchez and Maldonado (2010), we cannot propose a conclusive reason why their results differ from ours. We can only partially attribute the difference to the context related to TURF-based management in the region in which population studied in our experiments inhabits. We can presume that the process of governance and management of the natural resource performed in the real-world decision-making context faced by our subjects may promote more sustainable exploitation of the resource. Thus, some of players bring this context to the game exhibiting differences from other individuals tested in experiments performed in other Colombian villages.

Regarding sex of player, we observe that women's harvest decisions are less competitive than men (Croson and Gneezy, 2009).

The constant in this model provides the individual average harvest of participant when the remaining variables are zero during the rounds 1 to 10 of the experiment. This average ranges from 4.15 to 4.33 depending on the estimation. 


\section{Final Remarks}

This paper studies the behavior of fishermen from the Colombian Pacific in a CPR-game under a TURF-based management area. The findings show that human capital, measured by the years of schooling, has a significant negative relationship with the harvest. Under these results we consider that more schooled participants will diminish their harvest during the experiment leading to a cooperative solution. This process is endogenous and not motivated by external rules. We presume that the Allocative Effect of Schooling (Welch, 1970) and the effect of workshops conducted promoting sustainability in the region during the process of territorial management designation motivate this behavior.

According to Becker (1964), Bowen (1977), and Pallas (2000), formal education enhances the human capital stock by enhancing the ability to solve problems and adapt to new situations. In this experiment, it is observed that more schooled players presented an advantage over less schooled players, because, usually, more schooled players have the ability to effectively process payoffrelevant information, possibly subject to a more efficient strategy searching process.

It is also presumable that higher levels of schooling promote changes in preferences for the environment (Grossman and Krueger, 1995), and wealth effect promoted by higher human capital may change preferences for the environment in which fishermen are involved. Basically through a mechanism of transmission, we can presume that higher schooling increases the desire of fishermen for having better environmental and resource conditions

Finally, the role of sex as a determinant for decision-making does not have conclusive results. Revollo-Fernandez, Aguilar-Ibarra, Saenz-Arroyo and Micheli (2016) provide evidence for a greater cooperative attitude in women by changing their behavior towards lower harvest in the presence of regulations, sanctions or social scolding. However, Maldonado and Barrero (2016) show that sexsplit groups show no statistically significant differences in the overall harvesting, although mixed groups of women and men exhibit lower harvesting of the resource. Nevertheless, Cardenas, Rodriguez and Johnson (2011) show that somehow more sex-homogeneous groups exhibit larger collective contributions. Findings obtained in this current research only allow us arguing that women exhibit less competitive behavior than men in a CPR-game with no enforcement introduced.

\section{References}

Alesina, A. and La Ferrara, E. (2002). Who trusts others? Journal of Public Economics, 85, 207-234.

Almond, G.A. and Verba, S. (1963). The civic culture: Political attitudes and democracy in five nations. Princeton University Press.

Anderies, J.M., Janssen, M.A, Bousquet, F., Cardenas, J.C, Castillo, D. Lopez, M.C, Tobias, R., Vollan, R., and Wutich, A. (2011). The challenge of understanding decisions in experimental studies of common pool resource governance. Ecological Economics, 70(9), 1571-1579.

Arroyo-Mina, J.S., Revollo-Fernández, D.A., Aguilar-Ibarra, A., and Georgantzis, N. (2016). Economic behavior of fishers under climate-related uncertainty: Results from field experiments in Mexico and Colombia. Fisheries Research,183, 304-317

Brañas P., Cardenas, J.C., and Rossi, M. (2009). Gender, Education, and Reciprocal Generosity: Evidence from 1,500 Experiment Subjects. Society for the Study of Economic Inequality. Working Paper series, ECINEQ 2009-128.

Becker, G. (1964). Human Capital. Chicago: University of Chicago Press.

Boone, C., De Brabander, B., Carree, M., De Jong, G., Van Olffen, W., and Van Witteloostuijn, A. (2002). Locus of control and learning to cooperate in a prisoner's dilemma game. Personality and Individual Differences, 32(5), 929-946.

Bowen, H.R. (1977). Investment in Learning: The Individual and Social Value of American Higher Education. Jossey-Bass, San Francisco. USA.

Bowles, S., Gintis, H., and Osborne sêp, M. (2001). The determinants of earnings. Journal of Economic Literature, 39(4), 1137-1176

Brosig, J. (2002). Identifying cooperative behavior: some experimental results in a prisoner's dilemma game. Journal of Economic Behavior and Organization, 47(3), 275-290.

Burks, S.V., Carpenter, J.P. and Verhoogen, E. (2003). Playing both roles in the trust game. Journal of Economic Behavior and Organization, 51(2),195-216. 
Cancino, J.P., Uchida, H., and Wilen, J.D. (2007). TURF's and ITQs.s: Marine Resource Economics, 22, 391-406

Cardenas, J.C. (2003). Real wealth and experimental cooperation: evidence from field experiments. Journal of Development Economics, 70(2), 263-289.

Cardenas, J.C. (2001). How do groups solve local commons dilemmas? Lessons from experimental economics in the field. Environment, Development and Sustainability, 2(3), 305-322.

Cardenas, J.C., and Ostrom, E. (2004). What do people bring into the game: Experiments in the field about cooperation in the commons. Agricultural Systems, 82, 307-326.

Cardenas, J.C., Chong, A., and Ñopo, H. (2009). To what extent do Latin Americans trust, reciprocate, and cooperate? Comments evidence from experiments in six Latin American sepicountries. Economia, 9(2), 45-88.

Cardenas, J.C., Rodríguez, L., and Johnson, N. (2011). Collective action for watershed management: field experiments in Colombia and Kenya. Environment and Development Economics, 16( Special Issue 03), 275-303.

Christy, F. (1982). Territorial use rights in marine fisheries: definitions and conditions. FAO Fisheries Technical Paper 227, Rome: Food and Agriculture Organization.

CODECHOCÓ, Consejo Comunitario General Los Riscales, Grupo Interinstitucional y Comunitario de Pesca Artesanal-GICPA, Alcaldía Municipal de Nuquí, Fundación MarViva, Quibdó (2014). Propuesta de

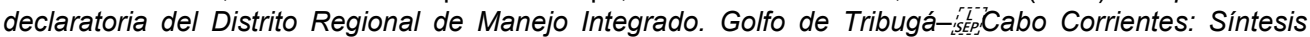
para su Justificación.

Croson, R., Gneezy, U. (2009). Gender differences in preferences. Journal of Economic Literature, 47(2), 448-474.

De Jong, G. (2015). The impact of social and human capital on individual cooperative behaviour. Implications for international strategic alliances. Critical Perspectives on International Business, 11(1), 4-29.

Diaz, J.M and Caro, N. (2016). El mar como territorio y la pesca como actividad tradicional en el Pacífico chocoano. In: J.M. Díaz, L. Guillot y M.C. Velandia (eds.), La pesca artesanal en la costa norte del Pacífico colombiano: un horizonte ambivalente. Fundación MarViva, Bogotá, pp. 45-57.

Dinda, S. (2008). Social capital in the creation of human capital and economic growth: A productive consumption approach. The Journal of Socio-Economics, 37, 2020-2033.

FAO (1995). Code of Conduct for Responsible Fisheries.Food and Agricultural Organization of the United Nations . Roma, Italia, $46 \mathrm{pp}$.

Fukuyama, F. (2002). Social capital and development: The coming agenda. SAIS Review, 22(1), 33-37.

Gaspart, F., and Seki, E. (2003). Cooperation, status seeking and competitive behaviour: Theory and evidence. Journal of Economic Behavior and Organization, 51, 51-77.

Georgantzis, N., Arroyo-Mina, J., and Guerrero, D. (2013). Studying Economics Reduces Overexploitation in a Common Resource Experiment. Theoretical Economics Letters, 3(5B), 31-39.

Grossman, G.M. and Krueguer, A.B. (1995). Economic growth and the environment. Quarterly Journal of Economics, 112, 353-378.

Lucas Jr., R.E. (1988). On the mechanics of economic development. Journal of Monetary Economics, 22, 3-42.

Maldonado J.H and Barrero, Y.M. (2015) Gender heterogeneity in user groups and fishing extraction: experimental evidence for a Caribbean Colombian marsh. 17th Annual BIOECON Conference experimental and behavioural economics and the conservation of biodiversity and ecosystem services. Cambridge, UK.

MinAgricultura (2013). Resolución 0899 del 29 de Julio de 2013. Ministerio de Agricultura y Desarrollo Rural, Colombia.

MinAgricultura, (2017). Resolución 2111 del 4 de octubre de 2017. Ministerio de Agricultura y Desarrollo Rural, Colombia.

Moreno-Sánchez R.P. and Maldonado, J.H. (2010). Evaluating the role of co-management in improving governance of marine protected areas: An experimental approach in the Colombian Caribbean. Ecological Economics, 69(12), 2557-2567.

Nguyen Thi Quynh, C., Schilizzi, S., Hailu, A., and Iftekhar, S. (2017). Territorial Use Rights for Fisheries (TURFs): State of the art and the road ahead. Marine Policy, 75, 41-52.

Ostrom, E., Gardner, R., and Walker, J.M. (1994). Rules, Games, and Common-Pool Resources. Ann Arbor.

Ostrom, E., Walker, J.M., and Gardner, R. (1992). Covenants with and without a sword: self-governance is possible. American Political Science Review, 86(2), 404-417.

Ostrom, E. and Walker, J.M. (1991). Communication in a commons: cooperation without external enforcement. In: Palfrey, T.R. (Ed.). Laboratory Research in Political Economy. University of Michigan Press, Ann Arbor, pp. 287-322.

Pallas, A.M. (2000). The effects of schooling on individual lives. In: Hallinan, Maureen T. (Ed.), Handbook of the Sociology of Education, pp. 499-526. Kluwer Academic/Plenum Publishers. New York.

Pallas, A.M. and Jennings, J.L. (2009). Cumulative knowledge about cumulative advantage. Swiss Journal of Sociology, 35, 211-229. 
Paulsen, R. (1991). Education, social class, and participation in collective action. Sociology of Education, 64(2), 96-110.

Putnam, R. (1995). Bowling alone: America's declining social capital. Journal of Democracy, 6, 65-78.

Revollo-Fernández, D.A., Aguilar-Ibarra, A., Sáenz-Arroyo, A., and Micheli, F. (2016). Exploring the role of gender in common-pool resources extraction: evidence from laboratory and field experiments in fisheries. Applied Economics Letters, 23(13), 912-920.

Santis, O. and Chavez, C. (2015) Quota compliance in TURFs: An experimental analysis on complementarities of formal and informal enforcement with changes in abundance. Ecological Economics, 120, 440-450.

Schramm, A.J.H.C. (1998), What Have We Learned From Experiments? Presidential Address, European Public Choice Society, Gothenburg.

Tan, J.H.W. and Zizzo, D.J. (2008). Groups, cooperation and conflict in games. The Journal of SocioEconomics, 37(2), 1-17.

Velez, M.A., Stranlund, J.K., and Murphy, J.J, (2009). What motivates common pool resource users? Experimental evidence from the field. Journal of Economic Behavior \& Organization, 70, 485-497.

Vieira, C.A., Diaz, M.C., and Diaz, J.M. (2016). Ordenamiento y manejo pesquero en la costa norte del Pacífico colombiano. In: J.M. Díaz, L. Guillot y M.C. Velandia (Eds.), La pesca artesanal en la costa norte del Pacífico colombiano: un horizonte ambivalente. Fundación MarViva, Bogotá, pp. 45-57.

Welch, F. (1970). Education in Production. Jorunal of Political Economics, 78, 35-59.

Wilen, J., Cancino, J., and Uchida, H., (2012). The economics of territorial use rights fisheries, or TURFs. Review of Environmental Economics and Policy, 6(2), 237-257.

Appendix A. Protocol and instructions

Appendix A1. Informative session

In this session it is explained what is a common pool resource (CPR). Examples of these natural resources are presented, and concepts of rivalry and non-exclusion are explained. Then, the game is introduced, and each player decides whether participating or not. After forming groups of 5 players, the context of the game is presented, sheets of individual choice payoffs are provided (See Appendix B and C), and the rules to be followed are given. Therefore it is explained that the game does not allow interactions among players, as well as how the individual payoff is obtained. In this session players are explained that payoffs are going to be converted to money. After making this introduction, three practice rounds are performed so players may understand the dynamics of experiment.

Appendix A2. Performance of experiment

Players are allowed to freely harvest. The researcher of each group sums individual harvest at the end of each round and communicates the aggregate harvest. Then each player annotates the payoff on the sheet. This procedure was repeated 10 rounds.

Appendix B. Individual Decision Sheet

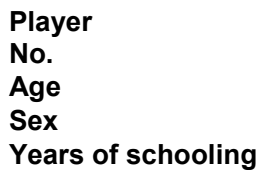

\begin{tabular}{|l|l|l|l|l|}
\hline Rounds & $\begin{array}{l}\text { A: Individual } \\
\text { Harvest }\end{array}$ & $\begin{array}{l}\text { B: Aggregate Harvest of } \\
\text { Group }\end{array}$ & $\begin{array}{l}\text { C (B-A): Aggregate Harvest } \\
\text { from Rivals }\end{array}$ & $\begin{array}{l}\text { D: } \\
\text { Payoff }\end{array}$ \\
\hline Practice 1 & & & & \\
\hline Practice 2 & & & & \\
\hline Practice 3 & & & & \\
\hline 1 & & & & \\
\hline 2 & & & & \\
\hline 3 & & & & \\
\hline$\ldots$ & & & & \\
\hline 10 & & & & \\
\hline Total & & & & \\
\hline
\end{tabular}


Appendix C. Payoffs Sheet

\begin{tabular}{|c|c|c|c|c|c|c|c|c|c|}
\hline & & MY AN & JNT OF & ARVES & & & & & \\
\hline & & 1 & 2 & 3 & 4 & 5 & 6 & 7 & 8 \\
\hline & 4 & 1,450 & 1,520 & 1,580 & 1,630 & 1,670 & 1,700 & 1,720 & 1,730 \\
\hline & 5 & 1,400 & 1,470 & 1,530 & 1,580 & 1,620 & 1,650 & 1,670 & 1,680 \\
\hline & 6 & 1,350 & 1,420 & 1,480 & 1,530 & 1,570 & 1,600 & 1,620 & 1,630 \\
\hline & 7 & 1,300 & 1,370 & 1,430 & 1,480 & 1,520 & 1,550 & 1,570 & 1,580 \\
\hline & 8 & 1,250 & 1,320 & 1,380 & 1,430 & 1,470 & 1,500 & 1,520 & 1,530 \\
\hline & 9 & 1,200 & 1,270 & 1,330 & 1,380 & 1,420 & 1,450 & 1,470 & 1,480 \\
\hline & 10 & 1,150 & 1,220 & 1,280 & 1,330 & 1,370 & 1,400 & 1,420 & 1,430 \\
\hline & 11 & 1,100 & 1,170 & 1,230 & 1,280 & 1,320 & 1,350 & 1,370 & 1,380 \\
\hline & 12 & 1,050 & 1,120 & 1,180 & 1,230 & 1,270 & 1,300 & 1,320 & 1,330 \\
\hline & 13 & 1,000 & 1,070 & 1,130 & 1,180 & 1,220 & 1,250 & 1,270 & 1,280 \\
\hline$\$$ & 14 & 950 & 1,020 & 1,080 & 1,130 & 1,170 & 1,200 & 1,220 & 1,230 \\
\hline $\boldsymbol{\alpha}$ & 15 & 900 & 970 & 1,030 & 1,080 & 1,120 & 1,150 & 1,170 & 1,180 \\
\hline 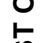 & 16 & 850 & 920 & 980 & 1,030 & 1,070 & 1,100 & 1,120 & 1,130 \\
\hline 山̆ & 17 & 800 & 870 & 930 & 980 & 1,020 & 1,050 & 1,070 & 1,080 \\
\hline$\frac{1}{4}$ & 18 & 750 & 820 & 880 & 930 & 970 & 1,000 & 1,020 & 1,030 \\
\hline Ш & 19 & 700 & 770 & 830 & 880 & 920 & 950 & 970 & 980 \\
\hline త్ర & 20 & 650 & 720 & 780 & 830 & 870 & 900 & 920 & 930 \\
\hline 步 & 21 & 600 & 670 & 730 & 780 & 820 & 850 & 870 & 880 \\
\hline & 22 & 550 & 620 & 680 & 730 & 770 & 800 & 820 & 830 \\
\hline & 23 & 500 & 570 & 630 & 680 & 720 & 750 & 770 & 780 \\
\hline & 24 & 450 & 520 & 580 & 630 & 670 & 700 & 720 & 730 \\
\hline & 25 & 400 & 470 & 530 & 580 & 620 & 650 & 670 & 680 \\
\hline & 26 & 350 & 420 & 480 & 530 & 570 & 600 & 620 & 630 \\
\hline & 27 & 300 & 370 & 430 & 480 & 520 & 550 & 570 & 580 \\
\hline & 28 & 250 & 320 & 380 & 430 & 470 & 500 & 520 & 530 \\
\hline & 29 & 200 & 270 & 330 & 380 & 420 & 450 & 470 & 480 \\
\hline & 30 & 150 & 220 & 280 & 330 & 370 & 400 & 420 & 430 \\
\hline & 31 & 100 & 170 & 230 & 280 & 320 & 350 & 370 & 380 \\
\hline & 32 & 50 & 120 & 180 & 230 & 270 & 300 & 320 & 330 \\
\hline
\end{tabular}

